\title{
圆 \\ The point prevalence of gastro-intestinal parasites in calves, sheep and goats in Magadi division, south-western Kenya
}

\author{
M.W. MAICHOMO ${ }^{1}$, J.M. KAGIRA ${ }^{1}$ and T. WALKER ${ }^{2}$
}

\begin{abstract}
MAICHOMO, M.W., KAGIRA, J.M. \& WALKER, T. 2004. The prevalence of gastro-intestinal parasites in calves, sheep and goats in Magadi division, south-western Kenya. Onderstepoort Journal of Veterinary Research, 71:257-261

Helminths cause great economic loss in livestock in Africa, and can be categorized as either direct or indirect losses. Arid and semi-arid lands (ASAL) in Kenya comprise $71 \%$ of total land area and harbour the largest population of cattle, sheep and goats. However, little information on the distribution and impact of gastro-intestinal (GIT) parasitism in these animals is available. This survey was conducted to establish the prevalence of GIT parasites infecting calves, sheep and goats and their relative importance in Magadi division, which is semi-arid. Faecal samples were obtained directly from the rectum of 109 calves, 133 goats and 20 sheep and submitted to the laboratory for faecal worm egg counts, and coccidial oocysts examination using a modified McMaster method. The significance of differences in mean egg count per gram (epg) between animal species and herds (farms) were assessed using analysis of variance. The overall prevalence of nematodes in the calves, sheep and goats was $69.2 \%, 80 \%$ and $82 \%$, respectively. About $10 \%$ of sheep and goats had epgs higher than 1000 , the remainder having light to moderate infections. The overall prevalence of coccidial oocysts in calves, sheep and goats was $30 \%, 44 \%$ and $45 \%$, respectively. Poor productivity in ASAL areas, where nutrition is often poor, is likely to be pronounced in the presence of parasite infections. These findings indicate that viable internal parasite control should be implemented in the study area in order to increase the productivity of the livestock there.
\end{abstract}

Keywords: Cattle, coccidia, gastro-intestinal parasites, goats, helminthosis, sheep

\section{INTRODUCTION}

Gastrointestinal (GIT) parasites constitute a major variable in livestock production systems, particularly in sheep and goats where these infections are the single greatest constraint to production in the tropics (Mukhebi, Shavulimo, Ruvuna \& Rurangirwa 1985). In Kenya, haemonchosis causes an annual loss of US\$26 million in sheep and goats, while

\footnotetext{
1 Kenya Trypanosomiasis Research Institute, P.O. Box 362, Kikuyu, Kenya

2 University of Georgia, College of Veterinary Medicine, Athens, Georgia, 30602, United States of America

Accepted for publication 15 March 2004-Editor
}

returns could be increased by as much as $470 \%$ by controlling the disease (Allonby 1975; Mukhebi et al. 1985). In most agro-climatic zones (ACZ) in Kenya, haemonchosis has been shown to be the leading cause of mortality in small ruminants (Kanyari 1993; Kagira \& Kanyari 2001). The most important genera of nematodes in Kenya are Haemonchus, Trichostrongylus, and Oesophagostomum (Gatongi 1995; Mwendia 1996).

Losses due to GIT parasitism can be categorized as direct or indirect. Direct losses are due to acute illness and death, forced premature slaughter and rejection of parts of the carcass at meat inspection in abattoirs. Acute parasitic conditions can be recognized and affected animals are generally treated 
by the farmer and thus direct losses can be avoided. In contrast, sub-clinical levels of parasitism cause indirect and more subtle losses and do not induce obvious clinical signs (Barger, Siale, Banks \& Le Jambre 1994). This type of parasitism is regarded as the most important cause of economic loss, as it is a flock or herd problem, unlike the acute syndrome, and tends to affect animals on a low plane of nutrition as well as lactating does and ewes. Subclinical levels of parasitism reduce potential productivity of sheep and reduce feed conversion (Ndarathi, Waghela \& Semenye 1989; Cobon \& O'Sullivan 1992; Suttle 1994). It is difficult to assess the economic effects of such subclinical infections but it is important to quantify them.

In Africa, ruminants are kept mainly for their meat, milk and skins. The production systems are diverse and are mainly dependent on the local climate. In pastoral areas of Kenya, the main breeds of livestock are of the indigenous type, which includes Zebu cattle, Red Maasai and Blackhead Somali sheep, and the East African goat. The productivity of these animals is limited mainly by the seasonal availability of feed and diseases (Semenye 1987; Baker, Lahlou-Kassi, Rege, Reynolds, Bekele, Mukasa-Mugerwa \& Rey 1992). Up-to-date information is lacking on the magnitude of GIT parasites in livestock maintained in traditional grazing systems in the Magadi division of Kenya, a semi arid region. Changing socio-cultural values among members of the Maasai community in the Magadi division have induced changes in their traditional lifestyle in that they now keep fewer but high-producing animals, which have been improved by cross breeding. However, due to greater susceptibility to parasites, the production of such "improved" crosses may be more severely affected by sub-clinical infection than in the case of the indigenous breeds, unless parasites are controlled through a well-managed herd health program. The present survey was undertaken to determine the prevalence and intensity of internal parasites in calves, sheep and goats in Magadi division, south-western Kenya, inhabited by the Maasai community.

\section{MATERIALS AND METHODS}

\section{Study area}

The Magadi division is in the Kajiado District of the Rift Valley Province, which is located $170 \mathrm{~km}$ southwest of Nairobi. The district lies between latitudes $1^{\circ} 10^{\prime}-3^{\circ} 10^{\prime} \mathrm{S} ; 36^{\circ} 5^{\prime}-37^{\circ} 55^{\prime} \mathrm{E}$. It occupies an area of $22106 \mathrm{~km}^{2}$ with an altitude that ranges from 650 $1500 \mathrm{~m}$ above sea level. The region is mainly semiarid with mean temperature ranges of $18-38{ }^{\circ} \mathrm{C}$. The mean annual rainfall is $440 \mathrm{~mm}$ and is distributed over two rainy seasons, which consists of the "long rains", from March to May and the "short rains", from October to December.

The vegetation types include:

(i) Tall grassland on deep alluvial soils

(ii) Tussocky annual grassland on deep alluvial soils

(iii) Shrubland on stony brecchia soils

(iv) Riverine and seasonally flooded woodland (Agnew 1996).

\section{Animal sampling and data collection}

A cross-sectional survey of 109 calves, 20 sheep and 133 goats from nine randomly selected herds (Munii, Mpesi, Lendulo, Nkedienye, Timoi, Kinoya, Lempaine, Sarara and Sadera) in Olkiramatian and Shompole communal group ranches (which border each other) of the Magadi division was done for two months from May to June 2002. All calves and half of the sheep and goats (randomly selected) in each herd were sampled only once. All calves were under 1 year of age while the sheep and goats were a mixture of weaners and adults. Faecal samples were obtained from the rectum and submitted to a laboratory for the determination of the number of nematode eggs per gram (epg) of faeces, using a modified McMaster technique (MAFF 1986). The presence of oocysts and Moniezia spp. ova was also recorded. Rainfall, temperature and humidity values were recorded daily from January to June 2002.

\section{Statistical analysis}

Data obtained was subjected to a univariate analysis of variance (ANOVA) to establish whether or not there were significant differences in mean $(\mu)$ epg of the animals.

\section{RESULTS}

\section{Climatic data}

From January to June $2002,565.2 \mathrm{~mm}$ of rainfall as recorded. The mean monthly temperature ranged between $21.7^{\circ} \mathrm{C}$ and $34^{\circ} \mathrm{C}$ and relative humidity from $56 \%$ in the morning to $35 \%$ in the afternoon. 


\section{Prevalence of nematodes}

Calves (Fig. 1)

A total of 109 calves were sampled. The overall mean prevalence of nematodes was $69.2 \%$. Trichostrongylid eggs were more common $(59.6 \%)$ than Strongyloides (27.4\%). Munii's herd had the highest mean epg of 250 while Mpesi's had the lowest mean epg of 23 (Table 1).

\section{Goats (Fig. 2)}

A total of 133 goats were sampled. The highest prevalence was recorded in the animals in the Munii and
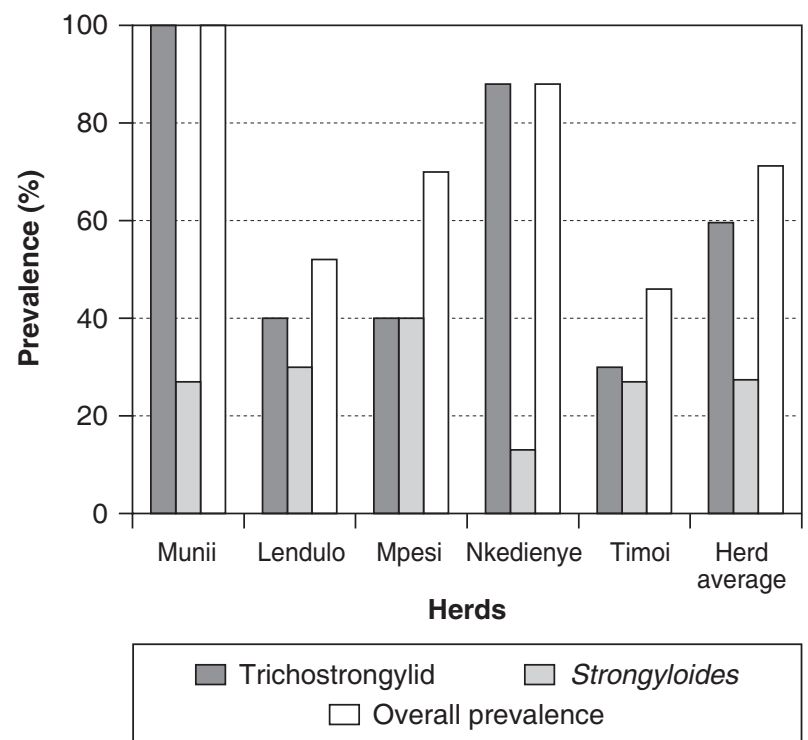

FIG.1 Prevalence of nematodes in calves from five herds in Magadi division

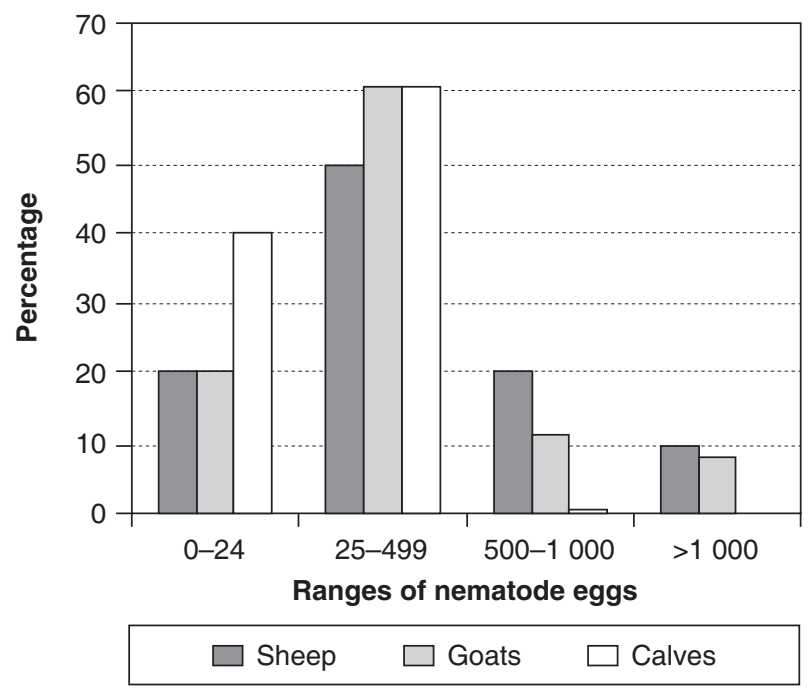

FIG. 3 Percentage of animals shedding various ranges of nematode eggs
Sarara herds while it was lowest in those in the Kinoya herd. The overall prevalence of nematodes was $82 \%$. Trichostrongylids and Strongyloides affected $72 \%$ and $43 \%$ of the goats, respectively. Mean epg values were highest in Munii and lowest in Kinoya herds (Table 1).

\section{Sheep}

Since only 20 sheep were sampled, the prevalence of nematodes was not assessed per herd. However, the overall flock prevalence was $80 \%$, with a mean epg of 326. Trichostrongylids and Strongyloides affected $75 \%$ and $45 \%$ of the sheep, respectively.

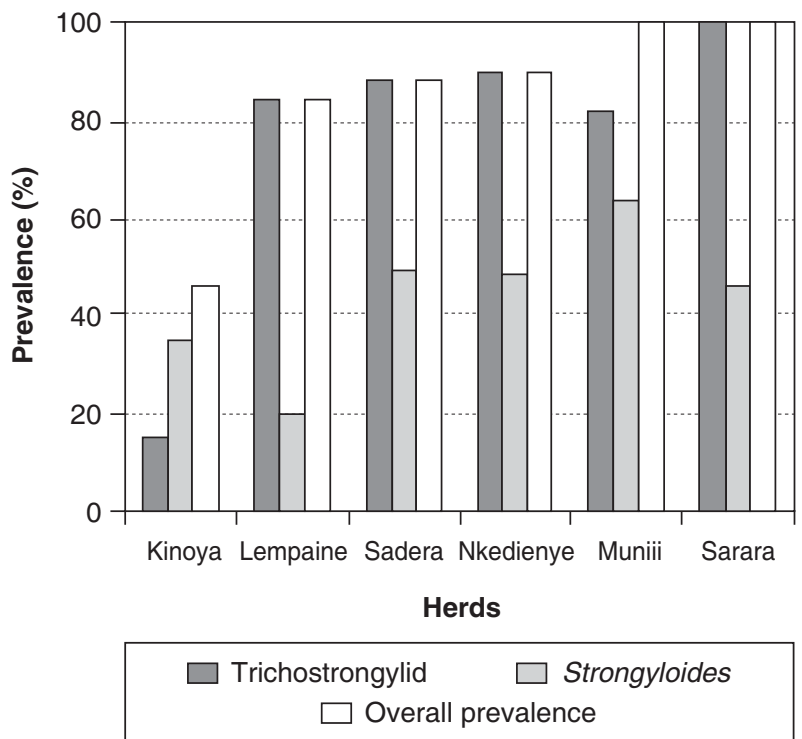

FIG. 2 Prevalence of nematodes in six herds of goats in Magadi division

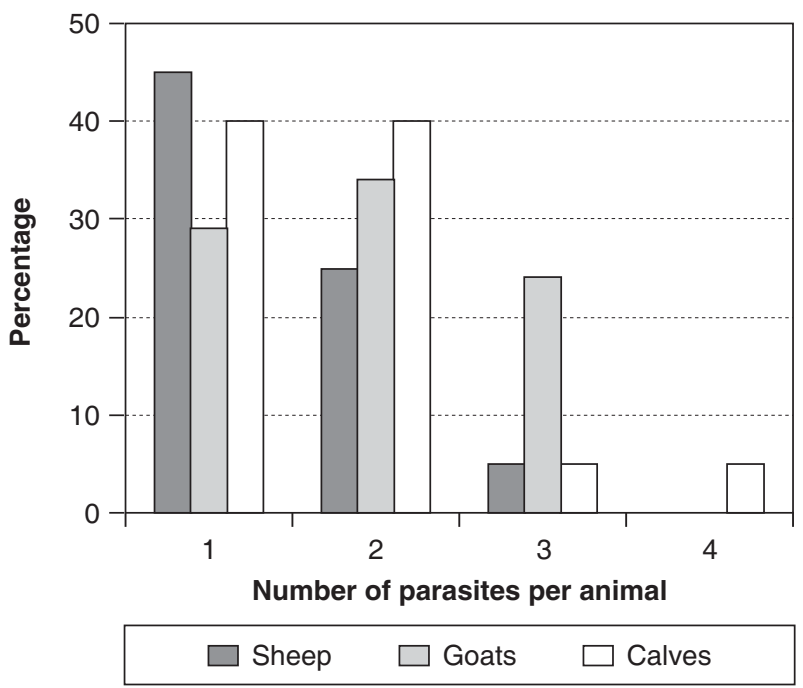

FIG. 4 Percentage of animals infected by a given number of parasites 
TABLE 1 Mean epg of total nematodes in calves, sheep and goats from different herds in Magadi division

\begin{tabular}{|l|r|r|r|}
\hline \multirow{2}{*}{ Herds } & \multicolumn{3}{|c|}{ Mean epg } \\
\cline { 2 - 4 } & Calves & Sheep & Goats \\
\hline Kinoya & - & 25 & 86 \\
Lempaine & - & 451 & 205 \\
Lendulo & 49 & - & - \\
Mpesi & 23 & - & - \\
Munii & 250 & - & 1118 \\
Nkedienye & 208 & - & 114 \\
Sadera & - & - & 780 \\
Sarara & - & 502 & 537 \\
Timoi & 55 & - & - \\
\hline
\end{tabular}

\section{Intensity of nematodes (Fig. 3)}

Most animals were lightly infected with ranges between 25 and 499 epg. Some sheep and goats, however, did have an epg above 1000.

\section{Other GIT parasites}

Coccidial oocysts and Moniezia spp. ova were also observed in some of the faecal samples. The overall prevalence of oocysts in the calves, goats and sheep was $30 \%, 44 \%$ and $45 \%$, respectively. The coccidial oocysts were not identified to genus level. Moniezia spp. eggs, which were also not identified to species level, were observed in $8 \%, 10 \%$ and $5 \%$ in the cattle, sheep and goats, respectively.

\section{Mixed infections}

The percentage of animals infected by a given number of GIT parasites, namely Trichostrongylid, Strongyloides, Moniezia spp. and coccidia are shown in Fig. 4. Most of the animals were infected with one or two species of parasites.

\section{Statistical analysis}

Significant differences between the numbers of epg of Trichostrongylid and Strongyloides were obtained $(P=0.000)$ with the former being higher $(\mu=314$, range $0-6300)$ than the latter $(\mu=106$, range $0-$ $7500)$. ANOVA results indicated that there were host differences in trichostrongylid epg levels $(P=$ $0.006, \mu=122$ in calves, 469 in goats and 320 in sheep), as well as sex differences in the animals with higher values in males $(P=0.0068)$. The hostlevel difference for Strongyloides epg levels were also significant $(P=0.0656)$, with goats having higher burdens $(\mu=173)$ than calves $(\mu=117.5)$ and sheep $(\mu=20.8)$. The Munii and Nkedienye herds, located in wetter areas, had larger numbers of animals infected with GIT parasites.

\section{DISCUSSION}

Livestock keeping is the most viable and self-sustaining enterprise in the pastoral community of Magadi division and is therefore their most important means of livelihood. For effective management of animal helminths, information on their epidemiology is essential (Herlich 1978). A previous study on helminthoses in small ruminants in this region (Mwendia 1996) revealed a lower mean epg level in the same season (after long rains) than those obtained in the present study. This could be due to the changing lifestyle of the local Maasai people from nomadic to sedentary, with emphasis on quality and economical beef production, necessitated by an increase in the human population and cost of living. Indeed, the prevalence of nematodes on herds in sedentary herds (Munii and Nkedienye) was higher than those of nomadic ones. The increase in helminthoses that was found could also be explained by an increase in the rainfall, being $562.6 \mathrm{~mm}$ in the first 6 months of 2002 compared to a total of 330 $\mathrm{mm}$ within the same period in 1994 (Mwendia 1996). However, faecal egg counts that were obtained in sheep in the present study were low compared to those reported in sheep in the highlands (Maingi 1996). The reason for this is believed to be the high temperatures and dry conditions in the pastoral areas, which lead to desiccation of nematode eggs and larvae. Inadequate nutrition, however, which is common in this area, may exacerbate the course of nematode infection. The animals are generally malnourished and suffer from other diseases, and are thus not resistant to nematode infection. Although the nematode eggs in this study were not identified to species level, Haemonchus contortus and Trichostrongylus colubriformis are considered to be the parasites most responsible for helminthoses in small ruminants in highlands and pastoral areas of Kenya, respectively (Gatongi 1995; Maingi, 1996; Mwendia 1996).

Sheep and goats had higher burdens when compared to calves. Cattle have been shown to have low nematode burdens up to 10 months of age, while the heaviest burdens are detected in 1.5 to 3 -yearold animals, thereafter declining to even lower burdens (Kaufman \& Pfister 1990). In the current study, most of the calves were about 1 year old. Since the study area has a high prevalence of trypanosomosis (Roderick, 1995), it is possible that animals suf- 
fering from both helminthoses and trypanosomosis will be more seriously affected. Studies in cattle and goats have shown that the pathogenicity of $\mathrm{H}$. contortus is increased in animals with concomitant experimental infection with Trypanosoma congolense (Griffin, Allonby \& Preston 1981; Kaufman, Dwinger, Hallebeck, Van Dijk \& Pfister 1992).

Mixed parasitic infections in hosts is the rule rather than the exception in most grazing systems as was demonstrated by the concurrent presence of up to four parasite genera. The occurrence of mixed infections may lead to decreased production due to the synergistic effect of each parasite, although this depends on the proportion of pathogenic species. The prevalence of coccidia in herds sampled ranged between $30 \%$ and $45 \%$. This is comparable to reports by Kanyari (1993) in sheep and goats. Some Eimeria species are considered pathogenic to the three host species studied. Although coccidiosis is regarded as a disease of housed or confined animals, lack of grazing pasture during the dry season may increase the "stocking rate" of animals on the few pastures remaining, a situation that may lead to a proliferation of oocysts.

It is concluded that gastrointestinal parasites that can cause economic losses are present in livestock in the study area. Further studies are needed to establish the seasonal epidemiology of these parasites and how they interact with trypanosomes in affecting production of ruminants. Such information will be important in designing an integrated control program for these parasites.

\section{ACKNOWLEDGEMENTS}

We thank Messrs Ken Otieno, Vincent Malonza, Njoroge Kisiango and Tiberius Marete for their technical assistance. The Maasai farmers at Nguruman allowed us to use their animals and the Director, $\mathrm{KETRI}$, gave permission to publish this work.

\section{REFERENCES}

AGNEW, A.D.Q. 1996. The graze and browse resource at Olkiramatian Group Ranch. Fourth report to KETRI/NRI on landscape/vegetation monitoring at Olkiramatian group ranch. Report to the ODA on a visit to the Kenya Trypanosomosis Research Institute (Nguruman station), May 1996. ODA: London.

ALLONBY, E.W. 1975. Investigation of small-stock diseases in Kenya. Interim technical report, sheep and goats development project. Rome: Food and Agriculture Organization of the United Nations.

BAKER, R.L., LAHLOU-KASSI, A., REGE, J.E.O., REYNOLDS, L., BEKELE, T., MUKASA-MUGERWA, E. \& REY, B. 1992
A review of genetic resistance to endoparasites in small ruminants and an outline of ILCA's research programme in this area. Proceedings of the $10^{\text {th }}$ Scientific Workshop of the Small Ruminant Collaborative Research Support Program, Nairobi, Kenya, SR-CRSP. Nairobi, Kenya.

BARGER, I.A., SIALE, K., BANKS, D.J.D. \& LE JAMBRE, L.F. 1994. Rotational grazing for control of gastrointestinal nematodes of goats in a wet tropical environment. Veterinary Parasitology, 53:109-116.

COBON, D.H. \& O'SULLIVAN, B.M. 1992. Effects of Haemonchus contortus on productivity of ewes, lambs and weaners in a semi-arid environment. Journal of Agricultural Science, 118:245-248.

GATONGI, P.M. 1995. The epidemiology and control of gastrointestinal nematodes of small ruminants in a semi-arid area of Kenya with emphasis on hypobiosis of Haemonchus contortus. Ph.D. thesis, McGill University, Canada.

GRIFFIN, L., ALLONBY, E.W. \& PRESTON, J.M. 1981. The interactions of Trypanosoma congolense and Haemonchus contortus infections in two breeds of goats. I. Parasitology. Journal of Comparative Pathology, 91:85-95.

HERLICH, H. 1978. The importance of helminth infections in ruminants. World animal Health Review, 26:26-29.

KANYARI, P.W.N. 1993. The relationship between coccidian and helminth infections in sheep and goats in Kenya. Veterinary Parasitology, 51:137-141.

KAGIRA, J.M. \& KANYARI, P.W.N. 2001. The role of parasitic diseases as causes of mortality in small ruminants in a highpotential farming area in central Kenya. Journal of the South African Veterinary Association, 72:147-149.

KAUFMANN, J. \& PFISTER, K. 1990. The seasonal epidemiology of gastrointestinal nematodes in Ndama cattle in Gambia. Veterinary Parasitology, 37:45-54

KAUFMANN, J., DWINGER, R.H., HALLEBECK, A., VAN DIJK, B. \& PFISTER, K. 1992. The interaction of Trypanosoma congolense and Haemonchus contortus in trypanotolerant cattle. Veterinary Parasitology, 43:157-170

MAFF. 1986. Ministry of Agriculture, Fisheries and Food. Manual of veterinary parasitological techniques, $3^{\text {rd }}$ ed. Reference book 418. London: Her Majesty's Stationery Office.

MAINGI, E.N. 1996. Anthelmintic resistance, epidemiology and control of gastrointestinal nematodes of small ruminant in Nyandarua district of Kenya and in Denmark. Ph.D. thesis, University of Nairobi.

MUKHEBI, A., SHAVULIMO, R.S., RUVUNA, F. \& RURANGIRWA, F. 1985. economics on internal parasitic control among goats in western Kenya. Proceedings of the $4^{\text {th }}$ Small Ruminant Collaborative Support Program (SR-CRSP) Scientific Workshop. ILRAD, Nairobi, Kenya, March 1985.

MWENDIA, C.M. 1996. Productivity and disease constraints of small ruminants in Maasailand, Kajiado district, Kenya. Ph.D. thesis, University of Reading.

NDARATHI, C.M., WAGHELA, S. \& SEMENYE, P.P. 1989. Helminthiasis in Maasai ranches in Kenya. Bulletin of Animal Health and Production in Africa, 37:205-208.

RODERICK, S. 1995. Pastoralist cattle productivity in a tsetse infested area of South West Kenya. Ph.D. thesis, University of Reading.

SEMENYE, P.P. 1987. Factors influencing Maasai cattle productivity in Kajiado district, Kenya. Ph.D. thesis, University of Nairobi.

SUTTLE, N.F. 1994. Seasonal infections and nutritional status. Proceedings of the Nutritional Society of England and Scotland, 53:545-555. 